\section{Transfer Mechanism}

A final comparison that helps to understand this emerging institutional form is the type of pathway, or transfer mechanism, that is offered to international students. A small number of pathway colleges ( 8 of 69 , or I2 percent) require students to reapply to the partner institution after completing the pathway program. But the vast majority of pathway colleges in Canada ( 88 percent) promise students direct entry to the partner university once they have successfully completed the pathway program. All of the corporately owned pathway colleges offer direct entry to one or more institutions. Direct entry is a valuable recruiting tool that corporate partners may require before entering formal relationships with universities.

\section{The pathway college relationship is be- coming commonplace among public Canadian universities: our research re- vealed that 69 of the 96 institutions, or 72 percent of Canadian universities, had an affiliation with at least one pathway college.}

\section{Discussion}

In light of the Canadian example, pathway colleges represent a significant new institutional form. Their impact on existing institutions is unclear at this point. However, we see the potential for an increased influence of private higher education models within countries with a strong public higher education sector, like Canada. Whereas differential tuition pricing for international and domestic students has already drawn attention to corporate pricing models, the pathway college model permits institutions and their governing boards to operate a "test case" for privatization within the walls of the public university, with many international and local examples to justify moving in this direction. This effect is already visible in the similarities in form between private pathway colleges and those owned by partner institutions. This is unsurprising, considering that pathway programs represent significant income generation for institutions, both by expanding their full fee paying international student population, and by adding an additional year of enrollment per student. At a systems level, these pathways potentially usurp international student tuition dollars from community colleges, which also actively seek to recruit students from abroad. In these ways, pathway colleges are already changing the higher education landscape.
Much more research is needed to gauge the full extent of pathway college influence. Within Canada, one concern is that pathway colleges may incentivize institutions to accept students who are unlikely to succeed in the partner institution. Another is that pathway college students will not receive the same academic or student services as those at the parent institution, potentially isolating them from counselling, ombudspersons, or other support systems. Similarly, preliminary examinations suggest that the pathway college emphasis on revenue generation (and in some cases profit) means that instructors and staff are more likely to be non-union and precarious. The need for more research is pressing, as the influence of pathway colleges on the public system as a whole may mean that pressures to compete will drive other institutions to adopt similar models.

Perhaps even more important is to examine these pathway colleges in the international context. Many of the corporate partners operate in several countries, inviting questions about how different policy regimes shape the resulting pathway colleges. We question how-or ifthese multinational companies standardize their pathways across the world, which would have implications not only for how we perceive the flows of international students, but also for the extent of global corporatization of this mobility, beyond what is typically understood as a matter of recruitment agents and admissions application preparation. We see pathway colleges as representative of a shift toward a postsecondary policy landscape that enables a more interdependent, international, and "flexibilized" model, challenging the assumptions of higher education systems and the notion of separate public/private sectors.

DOI: http://dx.doi.org/10.6oI7/ihe.2018.94.10520

\section{Inclusive Internationaliza- tion: Improving Access and Equity}

\section{HANS DE WIT AND Elspeth Jones}

Hans de Wit is director of the Center for International Higher Education, Boston College, US. E-mail: dewitj@bc.edu. Elspeth Jones is emerita professor, internationalisation of higher education, Leeds Beckett University, UK. E-mail: e.jones@leedsbeckett.ac.uk.

This article is an updated version of a contribution by the authors to University World News, 8 December 2017, Issue 486. 
Tnternationalization is not an isolated phenomenon in 1 higher education; it is embedded in the broader context of higher education in the global arena. Elitism, commercialization, high costs of study, corruption, fraud, and quantity versus quality are all common global themes in international higher education, influencing internationalization and vice versa. An inclusive approach must take into account the varied sociopolitical, economic, and demographic contexts in different parts of the world, and must address the issue that current internationalization policies and practices are not inclusive and leave out the great majority of students worldwide.

\section{Two Main Paradoxes}

In higher education, we are faced with two main paradoxes. First, while we may be striving to increase internationalization and global engagement, in many countries isolationist and nationalist trends result in a disconnect between local and global. Second, while credit and degree mobility is increasing globally, this billion-dollar industry reaches only a small student elite, leaving 99 percent of the world's student population behind.

Although still in its early stages throughout the emerging and developing world, massification has increased access to higher education. Access vs equity is an issue in general, but represents an even greater challenge for international education. We know the many benefits of international experiences as well as its many drivers. Yet, in some emerging and developing economies, degree mobility is only for I-2 percent of students and may have negative connotations, being seen as draining talent from the home country perspective.

Turning to credit mobility/study abroad, this has been seen as a key route toward internationalization for students. Yet outside Europe and the United States, the percentage of credit-mobile students is even lower than those seeking degrees. In other words, although mobility gets most attention in terms of internationalization policy and practice, only a very small number of students take part. Universities UK recently found students from higher managerial and professional backgrounds almost five times more likely to be mobile than students from long-term unemployment backgrounds. Furthermore, mobile students earn higher university grades and higher salaries than their nonmobile counterparts, meaning greater advantage to those already privileged. There is in addition a lack of representation in terms of income, ethnicity, migration history, or disability.

\section{INCREASING SHORT-TERM MOBILITY}

Increasing access to mobility is not easy, with funding a major constraint. One attempt to increase numbers is through more short-term opportunities. We know many benefits can accrue from even short-term mobility (work placement, study, or volunteering abroad), including transferable employability skills, e.g. team work, team leadership, organizational skills, project management, problem solving, networking, mediation skills, conflict resolution, decision making, and interpersonal skills. Short-term mobility can also develop intercultural competence skills such as willingness to take risks, patience, sensitivity, flexibility, openmindedness, humility, respect, and creativity.

The European mobility participation target for the 48 Bologna Process signature countries is 20 percent by 2020 , while in the United States, doubling study abroad numbers, as planned, would result in a similar percentage. Yet, even reaching these targets means that the majority of students, i.e. 80 percent, will not receive the benefits noted here. In emerging and developing countries, that percentage is closer to 99 percent. Mobility may be important and necessary, but it is insufficient to deliver inclusive internationalization.

\section{Short-term mobility can also develop intercultural competence skills such as willingness to take risks, patience, sen- sitivity, flexibility, open-mindedness, hu- mility, respect, and creativity.}

\section{Integrating Mobility into the Curriculum}

Importantly, we must see mobility as merely one aspect of the internationalized curriculum, which incorporates internationalized learning outcomes into its core, thus making internationalization available for all. Inviting students to reflect on their study abroad helps consolidate their own learning outcomes and contributes diversity of perspective for others. The same applies to actively engaging students from diverse geographical, national, linguistic, and cultural backgrounds in the classroom. This is an approach various commentators suggest we have still to fully utilize. It will not, in itself, internationalize the curriculum: a more fundamental review of program content, pedagogy, assessment, and learning outcomes is needed to achieve that. However, it supports the incorporation of alternative perspectives into learning, teaching, and assessment processes.

\section{Toward a More Inclusive Approach}

We believe internationalization policies fail to address all of those for whom they are intended and that there should be a renewed focus on students and staff who do not travel. Until we incorporate inclusive internationalization into the 
experience of all students, we run the risk of perpetuating the kind of elitism we try to fight. If we want to address these two paradoxes, focusing on mobility is counterproductive. It excludes the large majority of students, and confirms the nationalist-populist argument that it is, in fact, intellectual elitism.

Inclusive and comprehensive internationalization requires us to reframe our thinking, regardless of the context we live in. Internationalization for all should be the starting point for institutional strategies, reflecting an awareness that all students must be engaged in this agenda for their future lives as citizens and as professionals.

In summary, for internationalization to be inclusive and not elitist, it must address access and equity and requires us to:

- Incorporate internationalization at home as essential to internationaliation for all.

- Recognize, value, and utilize classroom diversity, bringing alternative perspectives to study programs-from international students, those returning from mobility experiences, and students from diverse communities in the local population.

- Involve the whole institution in delivering inclusive internationalization.

- Bridge the local and the global in research, education, and service.

- Focus on regional as well as global partnerships to help deliver an inclusive internationalization agenda.

DOI: http://dx.doi.org/ıo.6oI7/ihe.20I8.94.I052I

\section{Realizing the Benefits of Massification}

\section{FAZAL RızVı}

Fazal Rizvi is professor, Global Studies in Education, University of Melbourne, Australia.E-mail:frizvi@unimelb.edu.au.

This is a revised version of a paper published in Higher Education in Southeast Asia and Beyond (HESB), a publication of the Head Foundation in Singapore.

ince the beginning of this century, systems of higher $\checkmark$ education around the world have expanded rapidly. Not only middle-income, but also low-income countries have either already become "massified"-in terms of the definition provided by Trow (2006) - or are in the process of becoming so. Higher education is experiencing an unprecedented rate of growth in gross enrollment ratios (GER). As remarkable as this success story is, it should not be assumed that "massification" is unambiguously and necessarily a good thing. While any increase in student access to higher education is a cause for celebration, massification has given rise to a range of issues that should be more widely debated.

To begin with, it needs to be recognized that growth in GER in higher education often reflects an increasing level of economic prosperity and social and political confidence within various countries. As they become integrated into the global economy, they inevitably consider the expansion of their systems of higher education as necessary for them to take advantage of the global flows of capital, the shifting modes of production, and the global supply chains. Not surprisingly, therefore, governments around the world have

Has a pool of appropriately trained aca-
demic staff been available or been pre-
pared to look after the needs of new co-
horts of students, many of whom come
from families that lack traditions of
higher learning?

been prepared to allocate large sums of public money into higher education; facilitate greater private investment in the development of new universities and colleges; and encourage the public to view an investment in higher education as an outlay that is likely to bring good returns to both the individuals and the nation.

\section{Too RapID AND AD Hoc}

In this line of thinking, massification of higher education should clearly be welcomed, since it raises a country's level of education and signals its prosperity and prestige. It is, however, important to consider whether the speed of growth in GERs has not in fact been too rapid, and its form too ad hoc. We need to ask if the respective massifying systems of higher education have been able to cope with the pace of change. To what extent has the drive toward massification been stimulated by demand rather than by proper consideration of issues of supply-by opportunism rather than systematic processes of policy analysis and development?

As the demand for higher education among the rapidly growing middle class in developing economies has grown, we need to ask what kind of job governments have done in adequately preparing their public higher education institutions (HEIs) to expand-with appropriate levels of support, resource allocation, and capacity building. Has a pool of 